\title{
Factors Influencing the Response Rate and Survival of Testicular Germ Cell Tumors: A Single Institution Experience from Egypt
}

\author{
Hussam H. Zawam, Ahmed Selim, Nada O. Osman, Wael Edesa
}

Kasr Al-Ainy Center of Clinical Oncology and Nuclear Medicine, Faculty of Medicine, Cairo University, Cairo, Egypt

\begin{abstract}
Background: Testicular germ cell tumors (TGCTs) are the most common cancer in young adult males, and they represent one of the most curable solid tumors. The treatment modalities of different stages are variable among centers.

Aim: To describe the management of TGCTs and its outcome in an Egyptian cancer center.

Methods: The medical records of patients with TGCT treated between January 2012 and December 2016 were retrospectively reviewed. Thirty-two patients were included. Demographic, clinical, treatment, and outcome data were analyzed.

Results: The median age of the patients was 34.5 years. The most common presentation was unilateral painless testicular mass (87.5\%). Seminoma represented 53\% of cases and almost half of them had Stage I disease. For all patients, the clinical stage and International Germ Cell Cancer Collaborative Group (IGCCC) risk classification were significantly associated with survival outcomes. Five-year overall survival for stage I patients was $100 \%$, compared to $87.5 \%$ for stage II ( $<0.0001)$. Patients with good risk had a 5 -year OS of $87.4 \%$ while none of the poor risk group survived for 5 years $(\mathrm{p}=0.002$ ). The 5 -year disease-free survival for stage I was $83 \%$ for those who remained under active surveillance versus $87.5 \%$ for those who received adjuvant carboplatin $(\mathrm{p}=0.364)$.

Conclusions: Stage I TGCTs has an excellent overall survival regardless of the treatment modality received. In advanced disease, the clinical stage and IGCCC risk stratification remain valid prognostic risk factors.
\end{abstract}

Keywords: Testicular germ cell tumors, Treatment, Prognosis, Egypt

Corresponding author: Hussam Zawam, MD; Kasr Al-ainy Center of Clinical Oncology and Nuclear Medicine (NEMROCK), Cairo University Hospitals, Cairo 11511, Egypt; Email: husazawam@kasralainy.edu.eg

Submitted: 4-June-2021, Finally revised: 20-November-2021, Accepted: 9-December-2021, Published online: 20-January-2022

(cc) BY

\section{Introduction}

Testicular cancer is the most commonly diagnosed malignancy in young adult men ${ }^{1}$. There is marked geographical variation in the agestandardized incidence rate for testicular cancer, ranging from as low as $1.86 / 100,000$ in Egypt ${ }^{2}$ to as high as 9.2/100,000 in Denmark ${ }^{3}$.

Although the overall incidence of testicular tumors is rare (about $1 \%$ of all male malignancies), testicular germ cell tumors (TGCT) are the most common among them. In post pubertal males, 95\% of testicular tumors arise from germ cells and the majority of cases occur between the ages of 20 to 35 years ${ }^{4}$.
TGCTs are classified into seminoma and nonseminoma (NSGCT). Classic seminoma account for $50 \%$ of TGCT with peak age of $40-50$ years. NSGCT include embryonal carcinoma, yolk sac tumor, choriocarcinoma, teratoma, and mixed tumors ${ }^{5,6}$.

There is a paucity of data on testicular germ cell cancer management in Egypt. In the present study, our objective was to describe the treatment of these rare tumors in a single Egyptian institution and to determine factors that may impact survival results. This is expected to guide further improvement in the quality of care of our patients. 


\section{Methods}

This is a retrospective study of the medical records of patients with pathologically proven TGCTs who had been treated at Kasr Al-Ainy Center of Clinical Oncology and Nuclear Medicine (NEMROCK) from January 2012 to December 2016. Only patients with complete clinical data were enrolled in the present study.

The collected data included: demographic characteristics, date of diagnosis, presenting symptoms, comorbidities, pathological subtype, tumor size, clinical stage, tumor markers (alpha fetoprotein [AFP], Beta human chorionic gonadotropin [B-HCG], and lactate dehydrogenase [LDH]), treatment received, and survival outcome.

Staging was carried out according to the updated $8^{\text {th }}$ edition of the AJCC/UICC staging system for testicular cancer ${ }^{7}$. Stage IIA or higher were further stratified according to International Germ Cell Cancer Collaborative Group risk classification (IGCCC) into good, intermediate, and poor risk groups.

Radiotherapy for para-aortic lymph nodes was given as 3D conformal RT using A-P/P-A fields on a LINAC machine. The dose ranges from $21.6 \mathrm{~Gy} / 12$ fractions to $30 \mathrm{~Gy} / 15$.

Regarding response assessment, complete remission (CR) was defined as the absence of tumor mass by computerized tomography scan after chemotherapy or residual mass $<3 \mathrm{~cm}$ in seminoma or $<1 \mathrm{~cm}$ in NSGCT, with normal tumor markers. Partial remission (PR) was defined as having residual mass after chemotherapy that did not match the definition of $\mathrm{CR}$, while progressive disease (PD) was defined as growing mass or increasing markers.

\section{Statistical analysis}

Categorical variables were described as numbers and percentage and compared between groups using Chi-square / Fisher exact test. Abnormally-distributed continuous variables were described as median and range. The Kaplan-Meier method was used for survival analysis and survival curves were compared using the log-rank test. Disease-free survival (DFS) was calculated as the time of months elapsed between the date of achieving complete remission (after surgery and / or chemoradiotherapy) and the date of recurrence / death. Overall survival (OS) was calculated from the date of diagnosis to the date of death. A p-value less than 0.05 was considered significant.

The IBM SPSS software, version 23.0. (Armonk, NY: IBM Corp.) was used for data management and analysis.

\section{Results}

During the study period, 46 patients presented to our institute with the diagnosis of TGCT. Fourteen patients were excluded due to incomplete data and the remaining 32 patients were included.

All patients underwent a thorough clinical examination, scrotal ultrasound, computed tomography scan of the chest, abdomen, and pelvis with contrast and measurement of AFP, B-HCG, and LDH levles. All patients underwent upfront unilateral inguinal orchiectomy. The delay period from surgery to presentation to our department ranged from 3 to 62 days, with a median of 21 days. Details on the clinical and pathological characteristics of the studied population are presented in Table 1.

The first-line treatment received and the response to it according to different stages are presented in Table 2 . In the 3 patients with stage II who did not achieve CR, the retroperitoneal lymph nodes were the only site of residual disease. Those patients were successfully managed as follows: one patient with NSGCT underwent retroperitoneal lymph node dissection while the other 2 patients with seminoma, were treated by radiotherapy.

In patients with stage III diseases who did not achieve CR (3 with PR and 1 with progression); three patients with NSGCT had retroperitoneal residual disease and retroperitoneal lymph node dissection was performed, while the remaining patient developed brain metastasis and died from disease progression.

At the time of data analysis (June 2020), the median follow up of patients was 42.5 months (95\% CI: 23.0 - 63.1 months). Four (12.5\%) patients died; two from chemotherapy toxicity (septic shock) and the other 2 from disease progression (liver cell failure and respiratory failure).

The 5-year DFS and OS for the entire group was $76 \%$ and $84 \%$, respectively. The median DFS and OS were not yet reached. As shown in Table 4, the stage of disease and the IGCCC risk stratification were the only factors that had a significant impact on survival. Disease-free survival and os for patients with stage I were $86 \%$ and $100 \%$, vs $79 \%$ 
Table 1: Characteristics of 32 patients with testicular germ cell tumors

\begin{tabular}{|c|c|}
\hline Characteristic & $n(\%)$ \\
\hline \multicolumn{2}{|l|}{ Comorbidities } \\
\hline Ischemic heart disease & $3(9.4)$ \\
\hline Diabetes mellitus & $2(6.3)$ \\
\hline HCV infection & $2(6.3)$ \\
\hline Renal insufficiency & $1(3.1)$ \\
\hline None & $24(75)$ \\
\hline \multicolumn{2}{|l|}{ Side } \\
\hline Left & $17(53.1)$ \\
\hline Right & $15(46.9)$ \\
\hline History of undescended testis & $2(6.2)$ \\
\hline \multicolumn{2}{|l|}{ Clinical presentation } \\
\hline Unilateral painless testicular mass & $28(87.5)$ \\
\hline Flank pain & $2(6.25)$ \\
\hline Asymptomatic & $2(6.25)$ \\
\hline \multicolumn{2}{|l|}{ Stage } \\
\hline IA & $15(46.9)$ \\
\hline IB & $2(6.3)$ \\
\hline IIA & $1(3.1)$ \\
\hline IIB & 5 (15.6) \\
\hline IIC & $4(12.5)$ \\
\hline IIIB & $1(3.1)$ \\
\hline IIIC & $4(12.5)$ \\
\hline \multicolumn{2}{|l|}{ Pathological subtypes } \\
\hline Seminoma & $17(53.1)$ \\
\hline Classic seminoma & $15(46.9)$ \\
\hline Spermatocytic seminoma & $2(6.3)$ \\
\hline NSGCTs & $15(46.9)$ \\
\hline Yolk sac tumour & $1(3.1)$ \\
\hline Embryonal carcinoma & $1(3.1)$ \\
\hline Mixed & $13(40.6)$ \\
\hline Lymphovascular Invasion & $7(21.8)$ \\
\hline \multicolumn{2}{|l|}{ Elevated tumour markers (pre-surgery) } \\
\hline B-HCG & $10(31.2)$ \\
\hline AFP & $11(34.4)$ \\
\hline $\mathrm{LDH}$ & $10(31.2)$ \\
\hline \multicolumn{2}{|l|}{ IGCCC risk stratification (for stage $\geq$ IIA) } \\
\hline Good & $10(66.7)$ \\
\hline Intermediate & $2(13.3)$ \\
\hline \multirow[t]{2}{*}{ Poor } & $3(20)$ \\
\hline & $\begin{array}{l}\text { Median } \\
\text { (range) }\end{array}$ \\
\hline Age & $34.5(21-58)$ \\
\hline Tumor size in max dimensions (cm) & $5.8(1.5-14)$ \\
\hline
\end{tabular}

NSGCT: Nonseminomatous germ cell tumor, B-HCG: Beta human chorionic gonadotropin, AFP: Alphafetoprotein, LDH: Lactate dehydrogenase, IGCCC: International Germ Cell Cancer Collaborative Group and $87.5 \%$ for stage II $(\mathrm{p}<0.0001)$. Stage III patients were only 5 and survived for less than 5 years.

The relationship between achieving $\mathrm{CR}$ and the studied variables is shown in Table 3. The clinical stage was the only significant factor.

As presented in Figure 1, the 5-year DFS was $87.5 \%$ in patients who received adjuvant chemotherapy vs. $83 \%$ in patients kept on active surveillance only, with no statistically significance difference between the 2 groups $(\mathrm{p}=0.364)$.

Three patients (out of 17) with stage I had relapse (relapse rate 17.6\%). Two of them were under active surveillance, and one patient received adjuvant carboplatin. The median time to relapse was 20 months and para-aortic lymph nodes was the only site of relapse. All the 3 patients were successfully salvaged by BEP.

\section{Discussion}

Testicular germ cell tumors represent a heterogeneous group of neoplasms in terms of pathology, age at diagnosis, treatment modalities, and prognosis.

Although testicular cancer is a rare tumor (about $1 \%$ of all male malignancies), it represents one of the most curable solid tumors with a 10-year survival rate of $90-95 \%{ }^{3}$.

The median age of the patients included in this study was 34.5 years. Pure seminoma constituted $53 \%$ of our cases, while NSGCT represented $47 \%$. This coincides with the worldwide epidemiological incidence data in which classic seminoma account for $50 \%$ of testicular GCTs and the age ranges from 20-35 years ${ }^{5}$.

Fifty-three percent of our testicular germ cell tumor population presented with stage I. Active surveillance was adopted in $40 \%$ of patients, while the other $60 \%$ received active treatment. The 5 -year DFS was comparable in both groups. The relapse rate was $17.6 \%$, this matches data from numerous prospective studies that showed that the relapse rate is approximately in the range of $15 \%$ in unselected populations with stage I TGCT 8, 9 . However, a large retrospective analysis from the Danish group found that the relapse rate after orchiectomy in stage I NSGCT was $30.6 \%{ }^{3}$. Considering that Denmark is one of the few 
Table 2: First line treatment and response according to different stages for both seminoma and NSGCT

\begin{tabular}{|c|c|c|c|c|}
\hline \multirow[t]{2}{*}{ Stage } & \multicolumn{2}{|c|}{ First line treatment } & \multicolumn{2}{|c|}{ Response } \\
\hline & Regimen & $n(\%)$ & Criteria & $n(\%)$ \\
\hline \multirow[t]{4}{*}{ Stage I (n=17) } & Active surveillance & $7(41.2)$ & $\mathrm{CR}$ & $17(100)$ \\
\hline & Carboplatin AUC 7 x 1 & 5 (29.4), seminoma & & \\
\hline & BEP $\times 2$ & 4 (23.5), NSGCT & & \\
\hline & Radiotherapy to PALN & 1 (5.9), seminoma & & \\
\hline \multirow[t]{4}{*}{ Stage II (n=10) } & BEP x 4 & $6(60)$ & $\mathrm{CR}$ & $7(70)$ \\
\hline & $\mathrm{EP} \times 4$ & $2(20)$ & $\mathrm{PR}$ & $3(30)$ \\
\hline & VP x 4 (renal impairment) & $1(10)$ & & \\
\hline & Radiotherapy to PALN & $1(10)$ & & \\
\hline \multirow[t]{3}{*}{ Stage III $(n=5)$} & BEP x 3 (intermediate risk) & $2(40)$ & CR & $1(20)$ \\
\hline & BEP x 4 (poor risk) & $3(60)$ & $\mathrm{PR}$ & $3(60)$ \\
\hline & & & $\mathrm{PD}$ & $1(20)$ \\
\hline
\end{tabular}

AUC: Area under the curve, BEP: Bleomycin - etoposide - cisplatin, CR: Complete remission, NSGCT: Non-seminomatous germ cell tumor, PALN: Paraortic lymph nodes, PD: Progressive disease, PR: Partial remission, VP: vinblastine - paclitaxel

Table 3: The relationship between variables and the achievement of complete remission

\begin{tabular}{|c|c|c|c|}
\hline \multirow[t]{2}{*}{ Variable } & CR & No $C R$ & \multirow[t]{2}{*}{$p$ value } \\
\hline & $n(\%)$ & $n(\%)$ & \\
\hline \multicolumn{4}{|l|}{ Age } \\
\hline$\leq 35$ & $14(82.4)$ & $3(17.6)$ & \multirow[t]{2}{*}{0.678} \\
\hline$>35$ & $11(73.3)$ & 4 (26.7) & \\
\hline \multicolumn{4}{|l|}{ Comorbidities } \\
\hline No & $19(79.2)$ & $5(20.8)$ & \multirow[t]{2}{*}{1} \\
\hline Yes & $6(75)$ & $2(25)$ & \\
\hline \multicolumn{4}{|l|}{ Pathology } \\
\hline NSGCT & $11(73.3)$ & 4 (26.7) & \multirow[t]{2}{*}{0.678} \\
\hline Seminoma & $14(82.4)$ & $3(17.6)$ & \\
\hline \multicolumn{4}{|l|}{ Side } \\
\hline Left & $14(82.4)$ & $3(17.6)$ & \multirow[t]{2}{*}{0.678} \\
\hline Right & $11(73.3)$ & 4 (26.7) & \\
\hline \multicolumn{4}{|l|}{ Stage } \\
\hline I & $17(100)$ & 0 & \multirow[t]{3}{*}{0.001} \\
\hline II & $7(70)$ & $3(30)$ & \\
\hline III & $1(20)$ & $4(80)$ & \\
\hline \multicolumn{4}{|l|}{$\begin{array}{l}\text { IGCCC risk (for } \\
\text { stage }>\text { I) }\end{array}$} \\
\hline Good & $7(70)$ & $3(30)$ & \multirow[t]{3}{*}{0.103} \\
\hline Intermediate & $1(50)$ & $1(50)$ & \\
\hline Poor & 0 & $3(100)$ & \\
\hline
\end{tabular}

IGCCC: International Germ Cell Cancer Collaborative Group, NSGCT: Nonseminomatous germ cell tumor

countries in which all stage I patients are followed on a surveillance program, this explains their higher relapse rate. The median time to relapse in our patients was 20 months. In one of the largest published series by Mortensen et al., the median time to relapse in 1,954 patients with stage I seminoma was 13.7 months, but $22 \%$ of relapses occurred between 3 and 5 years ${ }^{10}$. Similar results were reported by the German Testicular Cancer Group ${ }^{11}$. Consequently, follow-up beyond 3 years is warranted. In our study, all the relapsed stage I patients were successfully salvaged by BEP and their 5-year DFS and OS were 83\% and 100\% respectively, comparable results have been published by Fischer et al ${ }^{12}$.

The Spanish Germ Cell Cancer Cooperative Study Group has developed a risk-adapted approach for the treatment of stage I testicular seminoma. It is based on tumor size and rete testis invasion, with surveillance reserved for low-risk patients and adjuvant 2 cycles of carboplatin for high-risk patients ${ }^{13}$.

Between 1950 and 1990, adjuvant radiotherapy was the standard treatment of stage I seminoma. However, growing evidence has raised concerns about the late effects of radiation therapy ${ }^{14}$. In the current study, only 2 patients with seminoma received radiotherapy. Travis et al. combined 14 population-based registries with more than 10,000 patients with stage I seminoma treated with 
Table 4: Univariate analysis of disease-free and overall survival

\begin{tabular}{|c|c|c|c|c|}
\hline \multirow[t]{2}{*}{ Variable } & \multicolumn{2}{|c|}{ 5-year DFS } & \multicolumn{2}{|c|}{ 5-year OS } \\
\hline & Rate & $\begin{array}{l}p \\
\text { value* }\end{array}$ & Rate & $\begin{array}{l}P \\
\text { value* }\end{array}$ \\
\hline \multicolumn{5}{|l|}{ Age } \\
\hline$\leq 35$ & $100 \%$ & \multirow[t]{2}{*}{0.016} & $78 \%$ & \multirow[t]{2}{*}{0.356} \\
\hline$>35$ & $80 \%$ & & $92 \%$ & \\
\hline \multicolumn{5}{|l|}{ Pathology } \\
\hline NSGCT & $100 \%$ & \multirow[t]{2}{*}{0.257} & $60 \%$ & \multirow[t]{2}{*}{0.103} \\
\hline Seminoma & $86 \%$ & & $94 \%$ & \\
\hline \multicolumn{5}{|l|}{ Side } \\
\hline Left & $92 \%$ & \multirow[t]{2}{*}{0.486} & $92 \%$ & \multirow[t]{2}{*}{0.25} \\
\hline Right & $88 \%$ & & $74 \%$ & \\
\hline \multicolumn{5}{|l|}{ Stage } \\
\hline I & $86 \%$ & \multirow[t]{3}{*}{0.245} & $100 \%$ & \multirow[t]{3}{*}{$<0.0001$} \\
\hline II & $100 \%$ & & $88 \%$ & \\
\hline III & $100 \%$ & & 0 & \\
\hline \multicolumn{5}{|l|}{ IGCCC risk ** } \\
\hline Good & ---- & \multirow[t]{2}{*}{----} & $88 \%$ & \multirow[t]{2}{*}{0.002} \\
\hline $\begin{array}{l}\text { Intermediate } \\
\text { / poor }\end{array}$ & --- & & 0 & \\
\hline
\end{tabular}

*Logrank test, ${ }^{* *}$ No DFS events, DFS: Disease-free survival, IGCCC: International Germ Cell Cancer Collaborative Group, OS: Overall survival

radiation therapy; the estimated cumulative 40 year risk of a second malignancy was $36 \%$ compared with $23 \%$ in the normal population ${ }^{15}$. With a median follow-up of 30 months (8-120), none of our patients developed second malignancy with either chemotherapy or radiotherapy.

In our series, patients with advanced stages (stage II and III) were 15 patients, 10 were of good risk, 2 with intermediate risk, and 3 with poor risk. Good-risk patients had a 5-year DFS and 5-year OS rate of $78.5 \%$ and $87.4 \%$, respectively. All of the 10 patients with good risk received chemotherapy, with the majority (6/10) had 3 cycles of BEP, while 4 patients received 4 cycles of EP regimen. The largest reported series from the Groupe d'Etude des Tumeurs Urogénitales (GETUG), Memorial Sloan Kettering Cancer Center (MSKCC), Swedish Norwegian Testicular Cancer Study Group, and UK Medical Research Council used four cycles of EP as a standard of care for the management of good-risk metastatic testicular GCT with very favorable

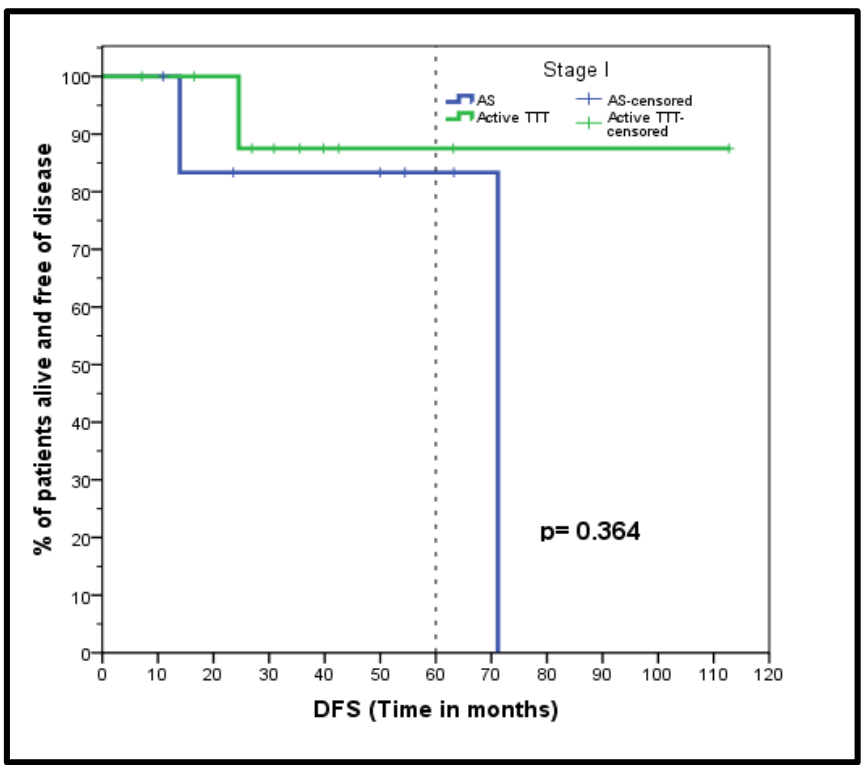

Figure 1: Kaplan-Meier curves of disease-free survival for stage I patients: active surveillance vs. active treatment

outcomes ${ }^{16-19}$. Similar efficacy has been reported with 3 cycles of BEP ${ }^{20}$.

In the current study, patients with NSGCT and retroperitoneal lymphadenopathy who did not achieve CR with chemotherapy were managed by RPLN dissection. None of the surgically managed cases had pure mature teratoma pathology. Although data from Heidenreich et al. showed that the incidence of finding mature teratoma in residual NSGCTs is about $40 \%{ }^{21}$. The group from Indiana University reported their long-term experience with 141 patients and from their patients who had retroperitoneal recurrence (4.5\%), the sole predictor of relapse and cancerspecific survival was the IGCCC risk classification ${ }^{22}$. Historically, the outcomes of patients with IGCCC with poor risk were disappointing, with 5-year PFS and OS rates of $41 \%$ and $48 \%$, respectively ${ }^{23}$. A more recent retrospective analysis of 223 poor prognosis patients reported 5-year PFS and OS rates of $55 \%$ and $64 \%$, respectively ${ }^{24}$. In the present study, we had only 3 patients with poor-risk IGCCC and all died within the first 2 years.

Our data should be taken with caution, given the retrospective nature of the study and the small number of patients. Better documentation of our patient's files is a must as we were not able to include 12 more patients due to insufficient data. 
Finally, integration of PET/CT in the assessment of response for our seminoma patients should be performed.

\section{Conclusion}

Stage I TGCTs has an excellent overall survival regardless of the treatment options. In advanced disease, the clinical stage and IGCCC risk stratification remain valid prognostic risk factors. Prospective studies are required for patients with poor risk NSGCT to improve their outcome.

\section{Acknowledgment \\ None. \\ Authors' contribution \\ Conception or design: HHZ, AS, WE; Acquisition, analysis, or interpretation of data: HHZ, NOO; Drafting or revising the manuscript: HHZ, WE; Approval of the manuscript version to be published: All authors; Agreement to be accountable for all aspects of the work: All authors.}

\section{Conflict of interest}

The authors declare that they have no conflict of interest to disclose.

\section{Data availability}

Deidentified individual participant data used to produce the results of this study are available from the corresponding author (HHZ) upon request.

\section{Ethical considerations}

This study was approved by the Research Committee of Kasr Al-Ainy Center of Clinical Oncology and Nuclear Medicine, Faculty of Medicine, Cairo University.

\section{Funding}

The authors did not receive funding for this study.

\section{Study registration}

None.

\section{References}

1. Chia VM, Quraishi SM, Devesa SS, Purdue MP, Cook MB, McGlynn KA. International trends in the incidence of testicular cancer, 1973-2002. Cancer Epidemiol Biomarkers Prev. 2010; 19(5): 1151-1159.

2. Ferlay J, Colombet M, Bray F. Cancer Incidence in Five Continents, CI5plus. IARC CancerBase No. 9. Lyon, France: International Agency for Research on Cancer; 2018. Available from: http://ci5.iarc.fr

3. Daugaard G, Kier MGG, Bandak M, et al. The Danish Testicular Cancer database. Clin Epidemiol. 2016; 8: 703-707.

4. Albers P. Management of stage I testis cancer. Eur Urol. 2007; 51(1): 34-43; discussion 43-4.

5. Bahrami A, Ro JY, Ayala AG. An overview of testicular germ cell tumors. Arch Pathol Lab Med. 2007; 131(8): 1267-1280.

6. Reuter VE. Origins and molecular biology of testicular germ cell tumors. Mod Pathol. 2005; 18(Suppl 2): S51-60.
7. Paner GP, Stadler WM, Hansel DE, Montironi R, Lin DW, Amin MB. Updates in the Eighth Edition of the Tumor-Node-Metastasis Staging Classification for Urologic Cancers. Eur Urol. 2018; 73(4): 560-569.

8. Daugaard G, Petersen PM, Rørth M. Surveillance in stage I testicular cancer. APMIS. 2003; 111(1): 76-83; discussion 83-85.

9. Germà-Lluch JR, Garcia del Muro X, et al. Clinical pattern and therapeutic results achieved in 1490 patients with germ-cell tumours of the testis: the experience of the Spanish Germ-Cell Cancer Group (GG). Eur Urol. 2002; 42(6): 553-62; discussion 562563.

10. Mortensen MS, Lauritsen J, Gundgaard MG, et al. A nationwide cohort study of stage I seminoma patients followed on a surveillance program. Eur Urol. 2014; 66(6): 1172-1178.

11. Dieckmann KP, Dralle-Filiz I, Matthies C, et al. Testicular seminoma clinical stage 1: treatment outcome on a routine care level. J Cancer Res Clin Oncol. 2016; 142(7): 1599-1607.

12. Fischer S, Tandstad T, Wheater M, et al. Outcome of men with relapse after adjuvant carboplatin for clinical stage I seminoma. J Clin Oncol. 2017; 35(2): 194-200.

13. Aparicio J, Germà JR, García del Muro X, et al. Riskadapted management for patients with clinical stage I seminoma: the Second Spanish Germ Cell Cancer Cooperative Group study. J Clin Oncol. 2005; 23(34): 8717-8723.

14. Chung P, Warde P. Stage I seminoma: adjuvant treatment is effective but is it necessary? J Natl Cancer Inst. 2011; 103(3): 194-196.

15. Travis LB, Fosså SD, Schonfeld SJ, et al. Second cancers among 40,576 testicular cancer patients: focus on long-term survivors. J Natl Cancer Inst. 2005; 97(18): 1354-1365.

16. Fizazi K, Delva R, Caty A, et al. A risk-adapted study of cisplatin and etoposide, with or without ifosfamide, in patients with metastatic seminoma: results of the GETUG S99 multicenter prospective study. Eur Urol. 2014; 65(2): 381-386.

17. Mencel PJ, Motzer RJ, Mazumdar M, Vlamis V, Bajorin DF, Bosl GJ. Advanced seminoma: treatment results, survival, and prognostic factors in 142 patients. J Clin Oncol. 1994; 12(1): 120-126.

18. Tandstad T, Smaaland R, Solberg A, et al. Management of seminomatous testicular cancer: a binational prospective population-based study from the Swedish Norwegian testicular cancer study group. J Clin Oncol. 2011; 29(6): 719-725.

19. Horwich A, Oliver RT, Wilkinson PM, et al. A medical research council randomized trial of single agent carboplatin versus etoposide and cisplatin for advanced metastatic seminoma. MRC Testicular Tumour Working Party. Br J Cancer. 2000; 83(12): 1623-1629.

20. Kawai K, Akaza H. Current status of chemotherapy in risk-adapted management for metastatic 
testicular germ cell cancer. Cancer Sci. 2010; 101(1): 22-28.

21. Heidenreich A, Pfister D, Witthuhn R, Thüer D, Albers P. Postchemotherapy retroperitoneal lymph node dissection in advanced testicular cancer: radical or modified template resection. Eur Urol. 2009; 55(1): 217-224.

22. Beck SDW, Foster RS, Bihrle R, Einhorn LH, Donohue JP. Pathologic findings and therapeutic outcome of desperation post-chemotherapy retroperitoneal lymph node dissection in advanced germ cell cancer. Urol Oncol. 2005; 23(6): 423-430.
23. International Germ Cell Consensus Classification: a prognostic factor-based staging system for metastatic germ cell cancers. International Germ Cell Cancer Collaborative Group. J Clin Oncol. 1997; 15(2): 594-603.

24. Kier MG, Lauritsen J, Mortensen MS, et al. Prognostic factors and treatment results after bleomycin, etoposide, and cisplatin in germ cell cancer: A population-based study. Eur Urol. 2017; 71(2): 290298. 